\title{
Simultaneous Determination of Nitrite and Nitrate Ions by Air-Segmented Amplitude-Modulated Multiplexed Flow Analysis
}

\author{
Haruka YoshIDA,* Koji InUI,* Masaki TAKEUCHI,** and Hideji TANaKA**† \\ *Faculty of Pharmaceutical Sciences, Tokushima University, 1-78-1 Shomachi, Tokushima 770-8505, Japan \\ **Institute of Health Biosciences, Tokushima University, 1-78-1 Shomachi, Tokushima 770-8505, Japan
}

\begin{abstract}
The concept of amplitude-modulated multiplexed flow analysis has been extended to the simultaneous determination of multiple analytes in a sample. A sample solution containing nitrite and nitrate ions is delivered from two channels, but the flow rates are varied at different frequencies. One of the channels has a reduction column for converting nitrate ions to nitrite ions. Downstream, the absorbance of the diazo-coupling product is monitored after the merging of both solutions with a Griess reagent. The signal is analyzed by a fast Fourier transform (FFT) in real time. From the thus-obtained amplitude, a $\mu \mathrm{mol} \mathrm{dm}{ }^{-3}$ level of the ions can be determined. The introduction of air bubbles is effective to reduce any axial dispersion, and hence to improve the sensitivity.
\end{abstract}

(Received February 15, 2012; Accepted March 25, 2012; Published May 10, 2012)

\section{Introduction}

Amplitude-modulated multiplexed flow analysis (AMMFA) is a new concept of continuous flow analysis. ${ }^{1}$ The flow rates of sample solutions to be merged are periodically varied at different frequencies. Downstream, the analytical signal, $V_{\mathrm{d}}$, is monitored and analyzed by a fast Fourier transform, FFT. Multiple samples can be analyzed simultaneously from the amplitudes of the wave components of interest. We have applied AMMFA to the determinations of food dyes, ${ }^{1}$ ferrous ion, ${ }^{1}$ chloride ion ${ }^{2}$ and nitrite ion. ${ }^{3}$ The segmentation of a liquid stream with air bubbles is effective to increase the sensitivity, because the bubbles act as barriers against the axial dispersion of analytes. ${ }^{3}$ The applications of AMMFA remained, however, a single analyte per sample. The purpose of the present study is, therefore, to extend the concept of AMMFA to the simultaneous determination of multiple analytes in a sample. We selected nitrite and nitrate ions as analytes, because their quantifications are of importance in the field of environmental water analysis.4-6 A sample solution containing the ions is fed through two channels, one of which has an inline reduction process. The proposed AMMFA with air-segmentation has made it possible to determine the $\mu \mathrm{mol} \mathrm{dm}{ }^{-3}$ level of the analytes from a single continuous analytical signal.

\section{Experimental}

\section{Flow system}

Figure 1 shows a schematic diagram of the flow system. Two channels (Channels 1 and 2) were used for delivering a sample solution, and one channel for a coloring reagent solution, unless otherwise stated. A Cd-Cu column $(\mathrm{C} ; 2.2 \mathrm{~mm}$ i.d. $\times 15 \mathrm{~cm}$

† To whom correspondence should be addressed.

E-mail: htanaka@ph.tokushima-u.ac.jp long, Ogawa \& Co., Japan) was set in Channel 1 in order to reduce nitrate ions to nitrite ions. Three peristaltic pumps $\left(\mathrm{P}_{1}-\mathrm{P}_{3}\right.$; Rainin Dynamax RP-1, USA) were used for delivering solutions, and one pump $\left(\mathrm{P}_{4}\right.$; the same model as $\left.\mathrm{P}_{1}-\mathrm{P}_{3}\right)$ for air. The pump tubes used were Pharmed $^{\circledR}$ tubings $(0.80 \mathrm{~mm}$ i.d. for $\mathrm{P}_{3}$ and $0.51 \mathrm{~mm}$ i.d. for others). The flow rates with $\mathrm{P}_{1}$ and $\mathrm{P}_{2}$ were varied in the range from 0 to $0.4 \mathrm{~cm}^{3} \mathrm{~min}^{-1}$ in response to sinusoidal control voltages $\left(V_{\mathrm{c} 1}\right.$ and $\left.V_{\mathrm{c} 2}\right)$, each having a different frequency (typically 0.03333 and $0.01666 \mathrm{~Hz}$ for $\mathrm{P}_{1}$ and $\mathrm{P}_{2}$, respectively). The voltages were generated from a signal generator (SG; NF Corp. WF1974, Japan). The total flow rate was kept constant at $1.0 \mathrm{~cm}^{3} \mathrm{~min}^{-1}$ with $\mathrm{P}_{3}$. Sample solutions were merged with a coloring reagent that was aspirated from the third channel. Air bubbles were introduced from the forth

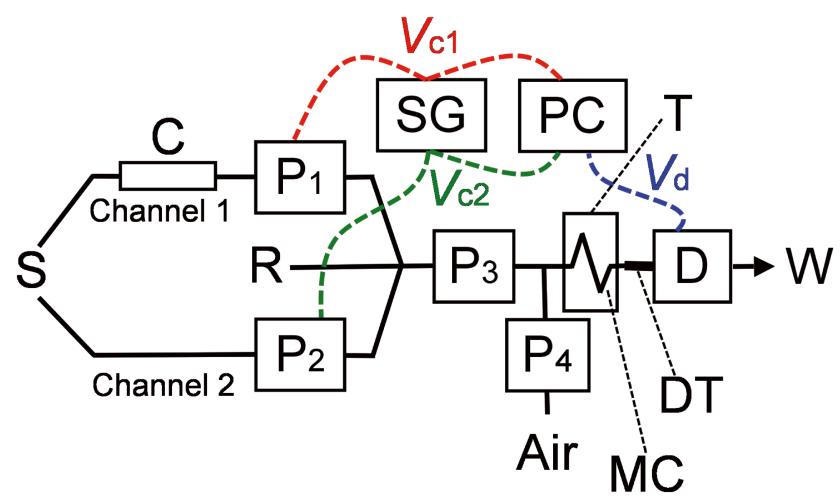

Fig. 1 Schematic diagram of the flow system. A three-channel system was used for the simultaneous determination of nitrite and nitrate ions. S, Sample solution; $\mathrm{R}$, reagent solution; $\mathrm{C}, \mathrm{Cd}-\mathrm{Cu}$ reduction column; w, waste; $\mathrm{P}_{1}-\mathrm{P}_{4}$, peristaltic pumps; $\mathrm{MC}$, mixing coil; T, thermostat bath; DT, deaeration tubing; D, spectrophotometer; $\mathrm{SG}$, signal generator; $\mathrm{PC}$, laptop computer with card type A/D-D/A converter; $V_{\mathrm{c} 1}$ and $V_{\mathrm{c} 2}$, controller output voltages; $V_{\mathrm{d}}$, detector output voltage. 
channel with $\mathrm{P}_{4}$ at a flow rate of $0.2 \mathrm{~cm}^{3} \mathrm{~min}^{-1}$ in order to segment the merged solution. Both fluids were propelled to a mixing coil $(\mathrm{MC} ; 0.8 \mathrm{~mm}$ i.d. $\times 0.5 \mathrm{~m})$ immersed in a thermostat bath $\left(\mathrm{T} ; 50^{\circ} \mathrm{C}\right)$. The temperature of the bath was controlled with an AS ONE CA061 heater, a Shinko PT100 resistance thermometer and a Shikoku-Riken ACS-13A PID controller. After the removal of air bubbles using a porous PTFE tubing (DT; Sumitomo Electric Fine Polymer TB-0201), the deaerated solution was introduced into a hand-made flow cell (quarts tubing; $1 \mathrm{~mm}$ optical path length), ${ }^{7}$ which was placed in a spectrophotometer (D; Shimadzu SPD-6AV, Japan). The detector output voltage $\left(V_{\mathrm{d}}, 0.8 \mathrm{~V} / \mathrm{AU}\right)$ as well as $V_{\mathrm{c} 1}$ and $V_{\mathrm{c} 2}$ were quantitized by an A/D-D/A converter (Measurement Computing, PC-CARD-DAS16/12-AO, USA) and acquired in a computer (PC; IBM ThinkPad R51e 1843-BLJ, USA) as a Microsoft Excel format. An in-house program written in Excel VBA was used for the acquisition, analysis and graphical display of the data. The previous program ${ }^{3}$ was improved so that it could remove noise from air bubbles that were accidentally introduced to the flow cell.

\section{Determination of analyte}

Nitrite ion was determined by a Griess method: ${ }^{8}$ a spectrophotometry at $538 \mathrm{~nm}$ based on the coupling of diazotized sulfanilamide and $N$-(1-naphthyl)ethylenediamine dihydrochloride (NED). ${ }^{9,10}$ An aqueous solution containing $0.24 \mathrm{mmol} \mathrm{dm}^{-3}$ sulfanilamide, $4 \mathrm{mmol} \mathrm{dm}^{-3} \mathrm{NED}$ and $0.6 \mathrm{~mol} \mathrm{dm}^{-3}$ hydrochloric acid was used as a coloring reagent. Nitrate ion needs to be reduced to nitrite ion before a measurement by the spectrophotometry.

Reagents of analytical reagent grade purchased from Kanto Chemicals (Tokyo) or Nacalai Tesque (Kyoto) were used without further purification. Zartorius Arium 611DI grade deionized water was used throughout.

\section{FFT analysis}

The principle of FFT for AMMFA was described in detail elsewhere. ${ }^{1}$ Briefly, if $V_{\mathrm{c} 1}$ and $V_{\mathrm{c} 2}$ for controlling sample flow rates are varied periodically, the analytical signal, $V_{\mathrm{d}}$, shows a periodic profile, the period of which equals to the least common multiple of the $V_{\mathrm{c} 1}$ and $V_{\mathrm{c} 2}$ periods. Figure 2A shows an example of real data for an aqueous solution containing nitrite and nitrate ions. The $V_{\mathrm{d}}$ period (i.e., $60 \mathrm{~s}$ ) is used as the length of the window for FFT analysis. Eight data obtained during $60 \mathrm{~s}$ are used for FFT analysis, as expressed by

$$
X_{\mathrm{k}}=\frac{1}{N} \sum_{\mathrm{n}=0}^{\mathrm{N}-1} x_{\mathrm{n}} \exp \left(-j \frac{2 \pi n k}{N}\right) \quad N=8
$$

where $j$ is an imaginary number. The total concentration of nitrate and nitrite ions can be determined from the amplitude of the second-harmonic wave component, $A_{2}\left(=2\left|X_{2}\right|\right)$, because the flow rate of Channel 1 , which has the $\mathrm{Cd}-\mathrm{Cu}$ column, is controlled by $V_{\mathrm{cl}}$ with a 30 -s period. The concentration of nitrite ion is determined from the amplitude of the fundamental wave component, $A_{1}\left(=2\left|X_{1}\right|\right)$, because the flow rate of Channel 2 , which has no pretreatment column, is controlled by $V_{\mathrm{c} 2}$ with a $60 \mathrm{~s}$ period. A temporal profile of the amplitudes are obtained in real time by moving the FFT window with time, as shown in Fig. $2 \mathrm{~B}$, where the obtained $A_{1}$ and $A_{2}$ values (mean \pm s.d., $n=60) \quad$ are $0.3162 \pm 0.0078$ and $0.5331 \pm 0.0059 \mathrm{~V}$, respectively.
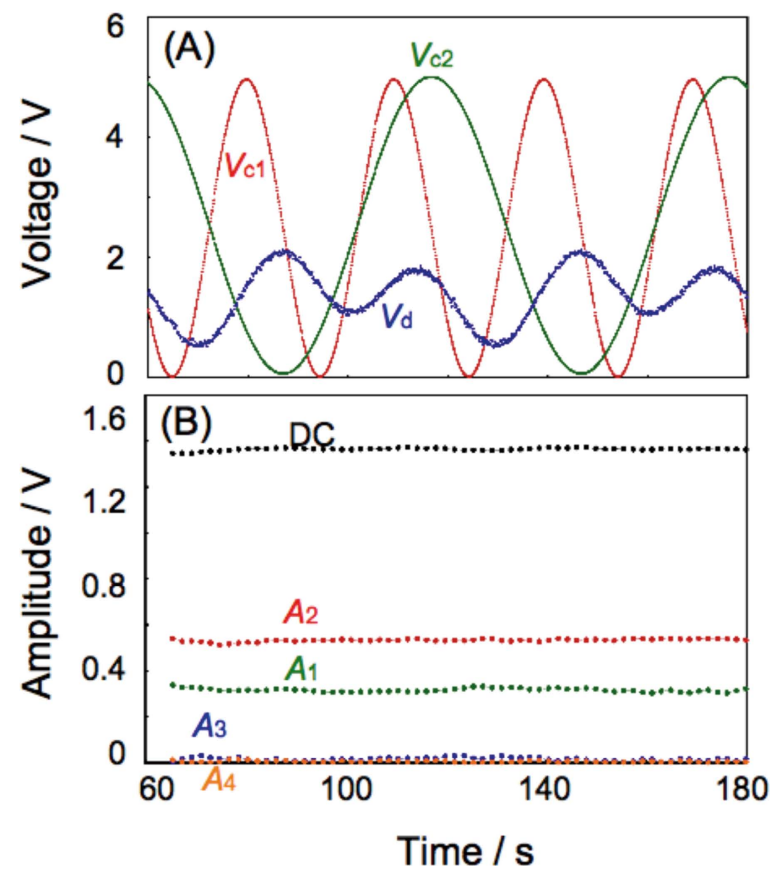

Fig. 2 (A) Typical flow signals of amplitude-modulated multiplexed flow analysis. $V_{\mathrm{c} 1}$ and $V_{\mathrm{c} 2}$, controller output voltages with periods of 30 and $60 \mathrm{~s}$, respectively; $V_{\mathrm{d}}$, detector output voltage; sample, aqueous solution containing $40 \mu \mathrm{mol} \mathrm{dm}{ }^{-3}$ nitrite ion and $80 \mu \mathrm{mol} \mathrm{dm}{ }^{-3}$ nitrate ion. (B) Tempolal profile of FFT analysis for the data shown in Fig. 2A. DC, direct current component. $A_{1}-A_{4}$, amplitudes of fundamental, second-harmonic, third-harmonic and fourth-harmonic wave components, respectively. Amplitudes for the third- and fourth-harmonic waves components $\left(A_{3}\left(=2\left|X_{3}\right|\right)\right.$ and $A_{4}\left(=\left|X_{4}\right|\right)$, respectively) obtained should theoretically be zero because there are no control signals with a period of 20 or $15 \mathrm{~s}$.

\section{Results and Discussion}

Optimization of analytical conditions for a coloring reaction The mixing coil length $(0-3 \mathrm{~m})$ and the reaction temperature $\left(30-60^{\circ} \mathrm{C}\right)$ were optimized. For this purpose, the $\mathrm{Cd}-\mathrm{Cu}$ reduction column was removed from Channel 1. A sample solution containing nitrite ion, and the coloring reagent solution were delivered from Channels 1 and 2, respectively. The flow rate of the former channel was varied from 0 to $0.375 \mathrm{~cm}^{3} \mathrm{~min}^{-1}$ with a period of $30 \mathrm{~s}$; that of the latter was held constant at $0.25 \mathrm{~cm}^{3} \mathrm{~min}^{-1}$. From the third line $(\mathrm{R})$, water was aspirated instead of the coloring reagent. The coil length was optimized to be $0.5 \mathrm{~m}$, because the highest amplitude was obtained under this condition. Shorter and longer coils were not appropriate because of insufficient coloration and amplitude damping through the dispersion, respectively. As for the coloration temperature, $50^{\circ} \mathrm{C}$ gave the highest amplitude; this temperature was selected as the optimum condition.

The performance of the $\mathrm{Cd}-\mathrm{Cu}$ column for the reduction of nitrate ion to nitrite ion was evaluated. It was confirmed that almost a $100 \%$ reduction efficiency was obtained for $10-40 \mu \mathrm{mol} \mathrm{dm}-3$ nitrate ions for at least $6 \mathrm{~h}$.

\section{Analytical performance}

Calibration curves were constructed from five standard solutions, each containing the same concentrations of nitrite and nitrate ions $\left(0,10,20,30\right.$, and $\left.40 \mu \mathrm{mol} \mathrm{dm}{ }^{-3}\right)$. The flow rates of $\mathrm{P}_{1}, \mathrm{P}_{2}, \mathrm{P}_{3}$ and $\mathrm{P}_{4}$ were $0-0.75$ (period: $30 \mathrm{~s}$ ), 0 - 0.75 (period: $20 \mathrm{~s}$ ), 2.00 and 0.67 (or closed) $\mathrm{cm}^{3} \mathrm{~min}^{-1}$, respectively. In this 
Table 1 Analytical performance of air-segmented amplitude-modulated flow analysis

\begin{tabular}{|c|c|c|c|c|}
\hline Mode & Analyte & Linear regression equation & $r^{2}$ & $\mathrm{LOD} / \mu \mathrm{mol} \mathrm{dm}{ }^{-3}$ \\
\hline \multirow[t]{2}{*}{ Air-segmented AMMFA (proposed method) } & $\mathrm{NO}_{2}^{-}+\mathrm{NO}_{3}^{-}$ & $A_{2}=0.00391 C_{\mathrm{T}}+0.0033$ & 0.9985 & 5.90 \\
\hline & $\mathrm{NO}_{2}^{-}$ & $A_{3}=0.00368 C_{\mathrm{NO}_{2}^{-}}-0.0010$ & 0.9992 & 2.16 \\
\hline \multirow[t]{2}{*}{ AMMFA (previous method) } & $\mathrm{NO}_{2}^{-}+\mathrm{NO}_{3}^{-}$ & $A_{2}=0.00322 C_{\mathrm{T}}+0.0001$ & 0.9974 & 7.80 \\
\hline & $\mathrm{NO}_{2}^{-}$ & $A_{3}=0.00255 C_{\mathrm{NO}_{2}^{-}}-0.0015$ & 0.9950 & 5.39 \\
\hline
\end{tabular}

AMMFA, amplitude modulated multiplexed flow analysis; $C_{\mathrm{NO}_{2}^{-}}$, concentration of nitrite ion in $\mu \mathrm{mol}_{\mathrm{dm}}^{-3}$; $C_{\mathrm{T}}$, total concentration of nitrite and nitrate ions in $\mu \mathrm{mol} \mathrm{dm}{ }^{-3} ; A_{2}$ and $A_{3}$, amplitudes of the second- and third-harmonic wave components, respectively, in the analytical signal.

Table 2 Determination of nitrite and nitrate ions in river-water samples

\begin{tabular}{|c|c|c|c|c|c|c|}
\hline \multirow{2}{*}{ Sample } & \multicolumn{3}{|c|}{ Nitrite ion } & \multicolumn{3}{|c|}{ Nitrate ion } \\
\hline & $\begin{array}{c}C_{\mathrm{NO}_{2}^{-}, \text {,add }} / \\
\mu \mathrm{mol} \mathrm{dm}^{-3}\end{array}$ & $\begin{array}{c}C_{\mathrm{NO}_{2}^{-}, \text {fnd }} / \\
\mu \mathrm{mol} \mathrm{dm}^{-3}\end{array}$ & $\begin{array}{c}\text { Rec., } \\
\%\end{array}$ & $\begin{array}{c}C_{\mathrm{NO}_{3}^{-}, \text {add }} / \\
\mu \mathrm{mol} \mathrm{dm}{ }^{-3}\end{array}$ & $\begin{array}{c}C_{\mathrm{NO}_{3}^{-}, \text {fnd }} / \\
\mu \mathrm{mol} \mathrm{dm}^{-3}\end{array}$ & $\begin{array}{c}\text { Rec., } \\
\%\end{array}$ \\
\hline Akui & 0 & $\mathrm{ND}^{\mathrm{a}}$ & - & 0 & 42.0 & - \\
\hline \multirow[t]{3}{*}{ River } & 30 & 30.3 & 97.5 & 0 & 41.3 & - \\
\hline & 0 & $(2.7)$ & - & 30 & 72.5 & 101.8 \\
\hline & 30 & 30.7 & 98.8 & 30 & 70.9 & 96.4 \\
\hline Yoshino & 0 & $(2.5)$ & - & 0 & 28.8 & - \\
\hline \multirow[t]{3}{*}{ River } & 30 & 32.5 & 100.0 & 0 & 28.5 & - \\
\hline & 0 & $(2.3)$ & - & 30 & 58.6 & 99.3 \\
\hline & 30 & 32.4 & 99.5 & 30 & 57.3 & 95.1 \\
\hline
\end{tabular}

Nitrite and nitrate ions were added as sodium potassium salts, respectively. The data in parentheses are below the limit of quantification.

a. The obtained value $\left(1.0 \mu \mathrm{mol} \mathrm{dm} \mathrm{dm}^{-3}\right)$ was below the LOD $(2.2 \mu \mathrm{mol}$ $\left.\mathrm{dm}^{-3}\right)$.

case, the amplitude of the second-harmonic wave component corresponds, therefore, to the total concentration of nitrite and nitrate ions $\left(0-80 \mu \mathrm{mol} \mathrm{dm}^{-3}\right)$ supplied from Channel 1 , which has the reducing column. On the other hand, that of the third-harmonic wave component corresponds to the concentration of nitrite ions alone $\left(0-40 \mu \mathrm{mol} \mathrm{dm}^{-3}\right)$ supplied from Channel 2 , which has no reducing column. The results are summarized in Table 1 together with those obtained through the previous method (AMMFA without air-segmentation). ${ }^{1,2}$ The linearity of the obtained calibration curves was good $\left(r^{2}>0.997\right)$. By introducing air-segmentation, sensitivity was increased by factors of 1.22 and 1.45 for the total and nitrite concentrations, respectively. The difference between the factors is attributed to that in the control period. That is, the effect of air-segmentation is more pronounced when the control period becomes shorter. ${ }^{3}$ The difference in the slopes for the total and nitrite concentration can also be attributed to that in the control period; amplitude damping is more significant when the control period becomes shorter. ${ }^{2}$ Table 2 gives the results of recovery tests for river-water samples. The concentration of nitrate ions was estimated from the difference between the total concentration (Channel 1) and the nitrite concentration (Channel 2). Good recoveries of around $100 \%$ were obtained for analytes spiked in the samples.

A number of methods have still been reported on the simultaneous determination of nitrite and nitrate ions in the flow mode, even since an excellent review by Moorcroft et al. ${ }^{11}$ These include, for example, flow injection analysis, ${ }^{12,13}$ sequential injection analysis ${ }^{14,15}$ and their analogous technique. ${ }^{16}$ Their basic configuration has two channels for a sample. That is, one has a reduction process and the other has no pretreatment process. Analytical signals for the total and nitrite concentrations are obtained sequentially, based on the difference in the residence time between the channels, or by switching the channels. The present study, where the amplitudes of the components in a single continuous analytical signal were used for quantifications, suggests an alternative approach to the conventional methods mentioned above.

\section{Acknowledgements}

This research was supported mainly by a Grand-in-Aid for Scientific Research (C) (21550083) from the Japan Society for the Promotion of Science (JSPS).

\section{References}

1. H. Tanaka, T. Mima, M. Takeuchi, and H. Iida, Talanta, 2008, 77, 576.

2. Y. Kurokawa, M. Takeuchi, and H. Tanaka, Anal. Sci., 2010, 26, 791.

3. K. Inui, T. Ogusu, M. Takeuchi, and H. Tanaka, Anal. Sci., 2011, 27, 305.

4. ISO 13395:1996, "Water Quality_Determination of Nitrite Nitrogen and Nitrate Nitrogen and the Sum of Both by Flow Analysis (CFA and FIA) and Spectrometric Detection", 1996, International Organization for Standardization, Geneva.

5. EPA Method 353.2, "Determination of Nitrate-Nitrite Nitrogen by Automated Colorimetry", 1993, United States Environmental Protection Agency, Washington, D.C.

6. JIS K 0102, "Testing Methods for Industrial Wastewater", 2010; K 0170-3, "Testing Methods for Water Quality by Flow Analysis-Part 3: Total Nitrogen", 2011, Japanese Industrial Standards Committee, Tokyo, Japan.

7. H. Tanaka, T. Tachibana, K. Aritsuka, and H. Chuman, J. Flow Inject. Anal., 2003, 20, 43.

8. J. P. Griess, Ber. Dtsch. Chem. Ges., 1879, 12, 426.

9. L. Ma, M. Oshima, S. Motomizu, and T. Hattori, Bunseki Kagaku, 1998, 47, 375.

10. M. Oshima, in "Yaku ni Tatsu Flow Injection Bunseki (Practical Flow Injection Analysis, in Japanese)", ed. K. Oguma, S. Motomizu, and T. Sakai, 2009, Mimizuku-sha, Tokyo, 59.

11. M. J. Moorcroft, J. Davies, and R. G. Compton, Talanta, 2001, 54, 785.

12. C. E. L. Pasquali, P. F. Hernando, and J. S. D. Alegría, Anal. Chim. Acta, 2007, 600, 177.

13. I. A. Tsoulfanides, G. Z. Tsogas, D. L. Giokas, and A. G. Vlessidis, Microchim. Acta, 2008, 160, 461.

14. S. Somnan, J. Jakmunee, K. Grudpan, N. Lenghor, and S. Motomizu, Anal. Sci., 2008, 24, 1599.

15. A. Ayala, L. O. Leal, L. Ferrer, and V. Cerdà, Microchem. J., 2012, 100, 55 .

16. C. Pons, J. L. M. Santos, J. L. F. C. Lima, R. Forteza, and V. Cerdà, Microchim. Acta, 2008, 161, 73. 